\title{
Gamicards - An Alternative Method for Paper-Prototyping the Design of Gamified Systems
}

\author{
Lauren S. Ferro, Steffen P. Walz, and Stefan Greuter \\ School of Media and Communication \\ Games and Experimental Entertainment Laboratory (GEElab) \\ RMIT University, Melbourne, Australia \\ \{lauren.ferro, steffen.walz, stefan.greuter\}armit.edu.au
}

\begin{abstract}
This paper introduces an early prototype concept known as Gamicards, for use in the design of gamified systems. With the popularity of gamified approaches and the varying knowledge of designers of these systems, not enough resources exist that can assist to guide designers through the process, ensuring important elements (such as motivation) are considered. Gamicards are an early prototype deck of cards that are designed to provide a resource for designers from a range of different backgrounds and knowledge of gamified design, with the intention to develop more meaningful gamified approaches.
\end{abstract}

Keywords: gamification, paper prototyping, game design, motivation, brainstorming, idea generation, personalization.

\section{Introduction}

Gamification is the application of game elements and game mechanics to make an ordinary task more engaging and enjoyable [1]. It has become popular across varying contexts from education, business, marketing, and social collaboration. The term engagement in this paper refers to the amount of time spent interacting with the gamified application, often with an increase after the implementation of a gamified approach. Gamification can use game elements and mechanics (i.e. badges, achievements) with the aim of increasing motivation to perform certain tasks, and is often successful. Motivation in the context of this paper refers to the users willingness to engage with the gamified application (this can be either extrinsic or intrinsic motivation $)^{1}$. Whether it is to improve product engagement, customer loyalty, [1], [2] or to develop a more enjoyable way of interacting or completing tasks such as keeping organised or productive, gamification can be a favourable strategy.

The implementation of a gamified approach has been evident in many situations such as marketing strategies (i.e. loyalty programs such as Fly Buys ${ }^{2}$ ) and educational

\footnotetext{
${ }^{1}$ It should be noted that the intention of this gamified intervention; the intrinsic motivation of the user is the primary focus.

${ }^{2}$ https : / / www. flybuys. com. au
} 
institutions (i.e. gold stars, house points) and online educational platforms (i.e. Khan Academy $^{3}$, DuoLingo ${ }^{4}$ and Memrise ${ }^{5}$ ), giving children a reward for completing household chores or good behaviour (i.e. Chore Wars) ${ }^{6}$. If you consider social activities such as Scouts, gamification is present in the form of collecting badges for acquired skills and completed tasks, social recognition, all playing a part in the development of a Scout [3]. It is through recent times that the term of "gamification" has become a buzzword and a favourable approach to "engaging" clients with new and exciting design schemes to maintain interest and promote a more enjoyable and ideally "fun" product [2]. Additionally, gamification can exist both in a physical sense (i.e. gold star stickers) as well as in a digital sense (i.e. badge and point reward systems) as an effective way to motivate and engage users. However, while the desire to modify and encourage specific user behaviour can be the trigger for using a gamified approach in the first place and that implementing a more enjoyable approach to ordinary tasks will make it more engaging; and while this is often successful, its success is not always long-term nor is the approach fresh.

\section{$2 \quad$ Who Are Designing These Systems?}

While, gamification approaches have been implemented across an array of areas, the designers who are creating these experiences may not have a background in game design, or gamification. The main difference between game design and a gamified approach is that the gamified approach is used for the design of real world situations, not artificial ones. Therefore, it is important that the designer is aware that such an approach produces outcomes that have real world effects and impacts the users motivations and behaviour - such as customer loyalty or productivity. Ultimately to what extent can only be viewed after users have engaged with the approach. However, these desired outcomes may be set by the designer, or stem from company objectives such as increased employee motivation which can be both positive and negative.

In some cases the thought of turning tasks into a gamified experience, can be an exciting process and the array of game elements and mechanics that can be used by the designer can be alluring. In some instances, the options of what game elements and mechanics to use may become overwhelming with designers opting for typical elements such as points and badges. This can become a problem if they are implemented without a meaningful purpose, as this may add an additional layer to a process that may interfere with the quality of user's engagement and enjoyment (if the points or badges become the driver of the task) if not taken into deeper consideration.

However, while people designing these systems can vary from inexperienced to experienced designers. Having two ends of the spectrum can be an important consideration in acknowledging that the designer's knowledge of using game elements and mechanics within a gamified approach varies as well. Therefore it is important to consider the diversity of design objectives as well as to provide adequate

\footnotetext{
${ }^{3}$ www. khanacademy. com

${ }^{4}$ Available online and as an application on smart devices. www . duolingo.com

${ }^{5}$ Available online and as an application on smart devices. www . memirse.com

${ }^{6}$ http: / / www . chorewars. com
} 
resources so that amateurs do not develop bad habits early on in the process, or to suggest alternative approaches for more experienced designers.

For instance, in an educational context, teachers may design and implement gamified strategies into a classroom activity with the intention to increase behaviours such as the timely submission of assignments or the productivity on assignment tasks in the way of gold stars or house points. A more recent example of this is with the not-for-profit online educational organisation, Khan Academy. As evident in Figure 1, the Khan Academy have implemented a range of different badge types for completing various types of assessment or loyalty such as returning to Khan Academy to complete more tasks. However, while students generally enjoy receiving rewards, a focus on receiving rewards can distract the student of the initial aim. For example, if you provide students with a badge for completing an essay, the quality of the essay may not be the focus, but rather completing the essay to get the badge. Students may accumulate a lot of badges, perhaps to compete with others, but it raises the question about what kind of impact has the badge had on the students understanding of essay writing. Implementing badges that reflect behaviours such as no grammatical errors, may fix this situation - thus encouraging students to proof read their work.

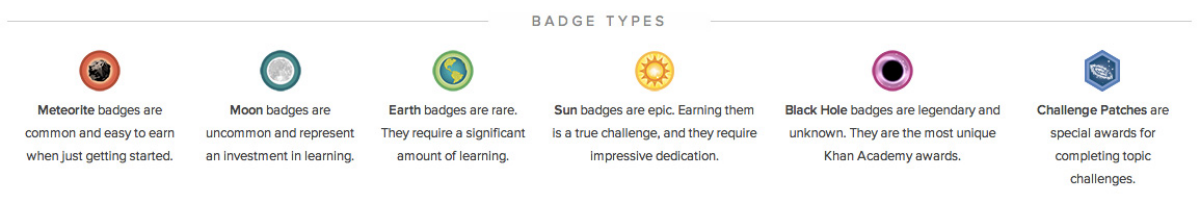

Fig. 1. Khan Academy badge types (left to right: Meteorite, Moon, Earth, Sun, Black Holes, Challenge Patches) ${ }^{7}$

\section{Resources for Designing Gamified Systems}

At present, few resources exist that can assist individuals to design a gamified approach as opposed to the design of games [4]-[6] most notably, Jesse Schell's deck (and book) of lenses [7]. However, while there are specific resources available such as GameOn!: Gamification Toolkit ${ }^{8}$, GameGame [8], Playful Experiences (PLEX) [9], [10] or simpler as Grow-a-Game and PlayGen ${ }^{10}$, there still needs to be a more concentrated resource for the design of gamified approaches aimed at both inexperienced and experienced designers. These resources provide support and assistance, while being diverse and open to many possible design options. While having the freedom to design any type of gamified approach can be a positive thing, it may become overwhelming to an inexperienced designer. Furthermore, if the design is based heavily around extrinsic and/or meaningless rewards, it may harm the longevity, user motivation and engagement with the gamified approach [11], [12].

\footnotetext{
${ }^{7}$ Badge icons taken from: https: / / www . khanacademy. org/badges

${ }^{8}$ http: //www.gameonlab.com/toolkit/

${ }^{9}$ Also available as an app on the App Store on iTunes.

http: / /www.tiltfactor.org/grow-a-game/

${ }^{10}$ http: //gamification.playgen.com/
} 


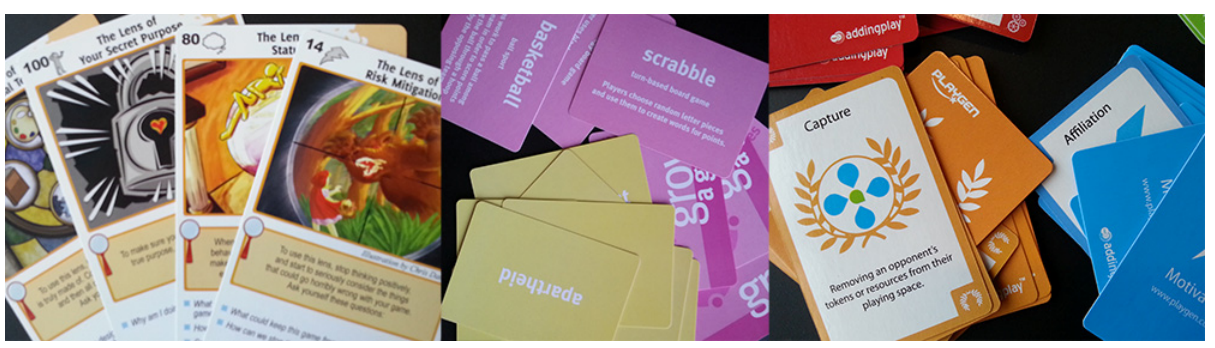

Fig. 2. (From left) Schell's deck of lenses, Grow-a-Game, PlayGen Deck

\subsection{The Need to Provide Resources for Non-game Designers}

Designers of gamified systems can range from educators to entrepreneurs with the vision of creating a more engaging approach to their given context. Having a diverse range if designers, also comes with a variation in knowledge and experience of gamified systems. With this in mind, it is important that if these systems are being implemented into contexts that cross over with real life expectations (i.e. improved academic performance) that they are carefully designed - much like the design of educational curriculum or a marketing strategy. Furthermore, the idea of what a game is may influence the general understanding of what is a gamified system. Industry experience has identified that individuals outside of a concentrated gaming and sometimes technology culture tend to perceive gamified approaches as either a waste of time or a potentially useful approach. Often the former, end up comparing gamified approaches to the idea of playing a game. Sometimes, the assumption is that a gamified approach is based entirely around that - a game. Therefore, it is important that there is an availability of adequate resources to provide support and an understanding of gamified systems and what it means to create a gamified approach that it is not necessarily "a game". The aim here is that by developing such an understanding this stigma centred on gamified design will be broken.

\section{Gamicards}

Gamicards are an early prototype deck of cards that are designed to provide a resource to assist individuals in the development of gamified approaches. It forms part of a larger project that is investigating the relationship between personality types and gamified experiences [13]. The cards aim at covering the fundamental and core considerations for developing more meaningful and personalised gamified approaches. Additionally, developing a vocabulary and awareness of the other types of elements that are available to use - making designers aware that they stem beyond the more popular: badge, achievements and points. By having resources with aspects focusing specifically on user considerations, it will keep the gamified approach focused, without being restricting. 
At present, Gamicards include five types of cards: (1) Game elements and Mechanics (2) User considerations (3) Context Cards (4) Motivation (5) Mystery Cards - for designers wanting to develop their own elements. Based on current data analysis from earlier work by Ferro et al. [13] the user considerations are expected to become more focused and inline with the development of a taxonomical relationship between users and associated game elements and mechanics. This taxonomical relationship aims to improve and strengthen a more meaningful interaction between the designer's choice of elements and mechanics, and the users experience with the gamified approach.

\subsection{Game Elements and Mechanics}

These cards consist of common elements and mechanics that are commonly found among various lists of game elements and mechanics [7], [14]-[16]. They range from rewards, badges and achievements, to other elements and mechanics such as leaderboards, points and status. Each card features a description that provides a brief outline about what the card is. This provides designers, who are unfamiliar with the terms, the ability to understand the element and to think about its potential in their gamified approach. The aim of providing a detailed resource is so designers can become aware of not only other existing game elements and mechanics but also be encouraged to think about ways to implement them.

\subsection{User Considerations}

These are the considerations that are most important when designing gamified experiences. They include the demographics of the user (i.e. who are they, where are they from, what are their intentions, etc.) objectives and outcomes (i.e. what is it that you want your users to achieve in a gamified system). User considerations can range in age, gender and location - which may influence, for example, the types of rewards administered or even virtual currency. While demographics tend to provide insight into the design of gamified approaches, the aim is to have a card specific to Users will help to place emphasis on this area of focus.

\subsection{Context}

Designers need to identify in the beginning, the context in which a gamified approach is targeting. For example, is the design within the context of education or is it within the context of business or marketing. The way that you would design an approach to motivate and engage student to submit homework on-time will vary in comparison to maintaining customer loyalty with purchasing certain brands. Furthermore, the motivation will also differ. In the case of loyalty programs consumers are often choosing to be a part of these gamified experiences. Where on the other hand, students are already participating in the educational curriculum and must complete their objectives to reach the defined outcomes; therefore the gamified approach is not so voluntary. This is an important consideration in the design of the gamified approach, as it is likely to be influenced by the context of which it is trying to be applied in. 


\subsection{Motivation}

The motivation of a user can influence the design of a gamified approach two-fold. For instance, the designer must determine if the gamified application is providing the source of motivation by extrinsic incentives or is it facilitating and encouraging intrinsic motivation. While the latter is harder to design for, determining whether the motivation of the users will be intrinsic or extrinsic can not only affect and influence the users motivation to begin with but also the longevity of the gamified approach. This has been evident with the implementation of unnecessary rewards for already motivating tasks [17]. For example, [17] outlines a study of children who were already intrinsically motivated to draw. However, when the children were introduced with a reward for drawing - a task that they were already intrinsically motivated to do, their desire to draw reduced. Therefore, if the motivation is focusing heavily on extrinsic rewards, the design approach may need to be reconsidered and the users identified in more detail, especially if the approach is aimed at a long-term behaviour change (i.e. healthier lifestyle). When designing a gamified approach to be applied within a learning context, considering if the chosen element and mechanics are encouraging extrinsic motivation is another example that may be an area of concern. As mentioned previously, this could be the difference between providing a badge to be purely obtained and collected by a student as opposed to linking it to behavior like checking for grammatical errors, thus encouraging more thorough proof reading.

\subsection{Mystery Cards}

These cards can be used for any other elements that the designer wishes to incorporate as part of the gamified approach.

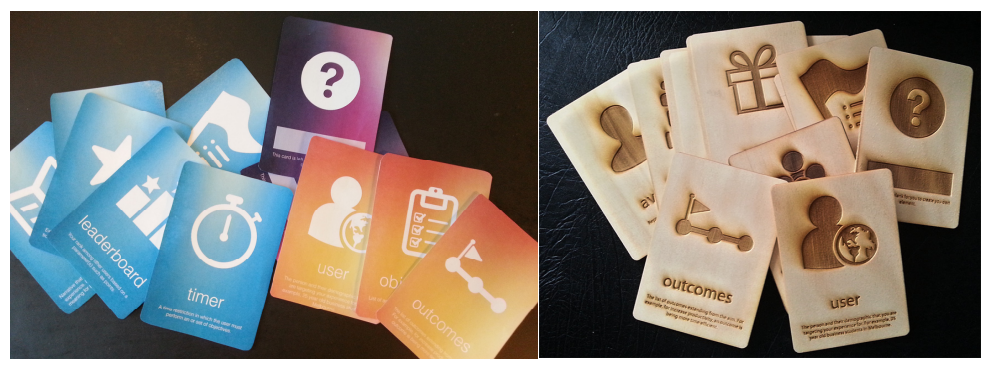

Fig. 3. Paper (left) and wooden (right) prototype

To use these cards together, a designer would first select the User Considerations cards and identify their target audience (i.e. basic demographics such as age, gender, location). Secondly, the designer would identify the Context of which their approach is to take place such as business, marketing, education, professional/personal development etc. Next, they would select the Motivation card and determine what kind of motivation that they aiming for such as long-term or short-term, to develop the user (i.e. healthier lifestyle) or to modify their behaviour (i.e. customer loyalty). Lastly they will identify what kind of elements and mechanics they would use to 
design the experience keeping the aforementioned details in mind and identifying if the choice of these elements and mechanics adhere to desired interaction(s). The designer is free to choose any elements from the array, even propose alternatives via the Mystery cards, but still have the visual representation outlining their objectives, bringing them back to the focus of their gamified approach.

\section{Discussion}

While no empirical research has yet to be conducted, preliminary interactions with the Gamicards looks promising. Inexperienced designers grasped the concept and design process quickly, understanding the basic concept of gamified design, while more experienced designers considered a range of different aspects that they would not necessarily have thought or focused directly on without the use of the cards. Thus for experienced designers, it has provided a complementary framework to their preexisting methods and knowledge and for inexperienced designers, these cards and resources have provided a foundation to develop their skills and understanding on how to implement game elements and mechanics into an experience. While Gamicards are very much in the early prototype stage, further testing and iterations are expected to provide more solid results. This is to be further reinforced with current research into the relationship between personality types and game elements and mechanics.

\section{References}

1. Deterding, S., Dixon, D., Khaled, R., Nacke, L.: From game design elements to gamefulness: Defining 'gamification'. In: Proceedings of the 15th International Academic MindTrek Conference: Envisioning Future Media Environments, New York, NY, USA, pp. 9-15 (2011)

2. Zichermann, G.: Gamification by design: Implementing game mechanics in web and mobile apps. O'Reilly Media, Sebastopol (2011)

3. L. to the Editor, "Boy Scouts of America had gamification down back in 1910." Letters to the Editor (2013)

4. Kultima, A., Niemelä, J., Paavilainen, J., Saarenpäa, H.: Designing 'Game Idea Generation' Games, Loading.. 3(5) (December 2009)

5. Alves, V., Roque, L.: A Deck for Sound Design in Games: Enhancements Based on a Design Exercise. In: Proceedings of the 8th International Conference on Advances in Computer Entertainment Technology, New York, NY, USA, p. 34:1-34:8 (2011)

6. Wetzel, R.: Introducing Pattern Cards for Mixed Reality Game Design. In: Third Workshop on Design Patterns in Games (2014)

7. Schell, J.: The art of game design a book of lenses. Elsevier/Morgan Kaufmann, Amsterdam, Boston (2008)

8. Järvinen, A.: Theory as Game: Designing the Gamegame. In: Changing Views: Worlds in Play (2005) 
9. Lucero, A., Holopainen, J., Ollila, E., Suomela, R., Karapanos, E.: The Playful Experiences (PLEX) Framework As a Guide for Expert Evaluation. In: Proceedings of the 6th International Conference on Designing Pleasurable Products and Interfaces, New York, NY, USA, pp. 221-230 (2013)

10. Arrasvuori, J., Boberg, M., Holopainen, J., Korhonen, H., Lucero, A., Montola, M.: Applying the PLEX Framework in Designing for Playfulness. In: Proceedings of the 2011 Conference on Designing Pleasurable Products and Interfaces, New York, USA, pp. 24:124:8 (2011)

11. Deci, E.L., Ryan, R.M.: Handbook of Self-determination Research. University Rochester Press (2002)

12. Deci, E.L., Ryan, R.M.: The 'What' and 'Why' of Goal Pursuits: Human Needs and the Self-Determination of Behavior. Psychol. Inq. 11(4), 227-268 (2000)

13. Ferro, L.S., Walz, S.P., Greuter, S.: Towards Personalised, Gamified Systems: An Investigation into Game Design, Personality and Player Typologies. In: Proceedings of The 9th Australasian Conference on Interactive Entertainment: Matters of Life and Death, New York, NY, USA, pp. 7:1-7:6 (2013)

14. Adams, E., Dormans, J.: Game mechanics: Advanced game design. New Riders, Berkeley (2012)

15. Sicart, M.: Defining game mechanics. Game Stud. 8(2) (2008)

16. Badgeville Announces Gamification Toolkit for World's Leading Enterprise Cloud Platform I badgeville.com, http://badgeville.com/news/announcements / badgeville-announces-gamification-toolkit-world\%E2\%80\%99sleading-enterprise-cloud-platfo (accessed: April 01, 2013)

17. Lepper, M.R., Greene, D., Nisbett, R.E.: Undermining children's intrinsic interest with extrinsic reward: A test of the 'overjustification' hypothesis. J. Pers. Soc. Psychol. 28(1), 129 (1973) 